Check for updates

Cite this: RSC Adv., 2021, 11, 15573

Received 25th March 2021

Accepted 20th April 2021

DOI: $10.1039 / \mathrm{d} 1 \mathrm{ra02377b}$

rsc.li/rsc-advances

\title{
Persulfate-activated charcoal mixture: an efficient oxidant for the synthesis of sulfonated benzo[d] [1,3]oxazines from $N$-(2-vinylphenyl)amides and thiols in aqueous solution $\dagger$
}

\begin{abstract}
Palani Natarajan, $\mathbb{D}$ * Priya and Deachen Chuskit
A series of 2,4-aryl-4-((arylsulfonyl)methyl)-4H-benzo[d][1,3]oxazines in good to excellent yields have directly been obtained from $\mathrm{N}$-(2-vinylphenyl)amides and thiols by employing a mixture of $\mathrm{K}_{2} \mathrm{~S}_{2} \mathrm{O}_{8}$ activated charcoal in aqueous acetonitrile solution at $50{ }^{\circ} \mathrm{C}$. A plausible mechanism for the reaction is reported. It reveals that the reaction follows a radical pathway and the persulfate has been the oxygen source for formation of the sulfone group in the products. It is worth mentioning that this protocol utilizes an easily accessible $\mathrm{K}_{2} \mathrm{~S}_{2} \mathrm{O}_{8}$-activated charcoal mixture and thiols, respectively, as an oxidant and sulfonylating precursors for the first time.
\end{abstract}

\section{Introduction}

Benzoxazines and their derivatives are an important class of heterocycles frequently found in many natural products ${ }^{1}$ and biologically active compounds ${ }^{2}$ (e.g. 6-chloro- $N$-ethyl-4-methyl4-phenyl-4H-benzo[ $d][1,3]$ oxazin-2-amine and 2-chloro-1(2,2,4,4-tetramethyl-2H-benzo[ $d][1,3]$ oxazin-1(4H)-yl)ethanone). Likewise, as the key structural motif changes the physical and chemical properties of the parent molecule, the sulfone $\left(-\mathrm{SO}_{2}-\right)$ functionality has widely been installed in a variety of functional materials $^{3}$ (pristine polysulfone networks) and $\operatorname{drugs}^{4}$ (dapsone, diazoxide and sulfisoxazole). Therefore, development of a practical method for the synthesis of sulfonated benzo[d][1,3]oxazines has drawn significant attention from chemists, pharmacists and biologists. In 2018, Wu and co-workers ${ }^{5}$ reported visible-light photocatalysis for the preparation of sulfonated benzo[ $[d][1,3]$ oxazines from $N$-(2-vinylphenyl)amides, DABCO $\cdot\left(\mathrm{SO}_{2}\right)_{2}$ and diazonium salts (Scheme 1a). ${ }^{5}$ Similarly, the acid-mediated oxythiolation of $o$-vinylanilides with $\mathrm{N}$-(arylthio)succinimides and $m$-CPBA was reported by the Anbarasan group in 2018 (Scheme 1b). ${ }^{6}$ In 2019, Li and co-workers ${ }^{7}$ disclosed a metal-catalyzed approach for the synthesis of sulfonated benzo[ $d][1,3]$ oxazines from $N$-(2-vinylphenyl)amides and alky1(aryl)sulfinates (Scheme 1c). ${ }^{7}$ Last year, Huang et al. ${ }^{8}$ described an electrochemical method for the synthesis of sulfonated benzo[ $d][1,3]$ oxazines from $N$-(2-vinylphenyl)amides and sulfonyl hydrazines, $c f$. Scheme $1 \mathrm{~d} .^{8}$

Department of Chemistry \& Centre for Advanced Studies in Chemistry, Panjab University, Chandigarh-160014, India.E-mail: pnataraj@pu.ac.in

$\dagger$ Electronic supplementary information (ESI) available: General aspects, procedure, experimental characterization data and copies of ${ }^{1} \mathrm{H}$ and ${ }^{13} \mathrm{C}$ NMR spectra for products. See DOI: 10.1039/d1ra02377b
Persulfate $\left(\mathrm{S}_{2} \mathrm{O}_{8}{ }^{2-}\right.$, also known as peroxydisulfate or peroxodisulfate) as readily available and efficient oxidizing reagent has extensively been utilized for organic synthesis ${ }^{9}$ and environmental remediation ${ }^{10}$ in recent decades. Persulfate is a white crystalline solid, cheap, chemically stable at ambient conditions, easy-to handle and convenient to transport. Moreover, upon activation ${ }^{11}$ by heat, metal ions, carbon materials, base, or

a) synthesis of sulfonated benzoxazines via photoredox catalysis

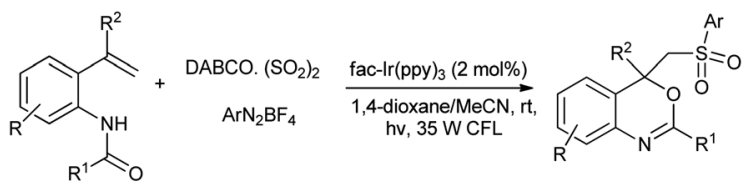

b) synthesis of sulphonated benzoxazines via oxychalcogenation<smiles>C=C(c1ccccc1)c1cc(OC)ccc1NC(=O)c1ccccc1</smiles>

c) synthesis of sulfonated benzoxazines via silver or cerium mediation
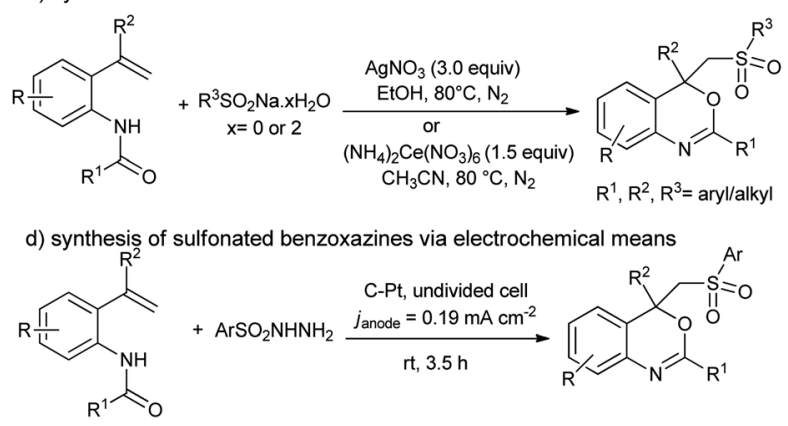

Scheme 1 Various protocols for the synthesis of sulfonated benzo[d] $[1,3]$ oxazines yet reported in literature. 


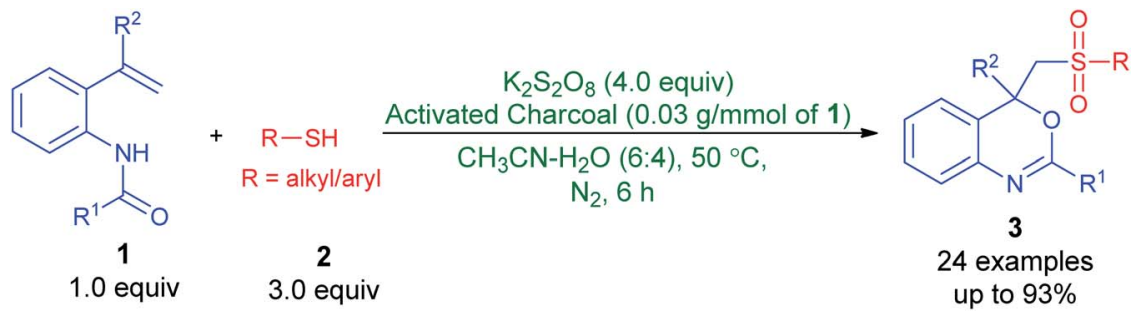

Scheme 2 The synthesis of 2,4-aryl-4-((arylsulfonyl)methyl)-4H-benzo[d][1,3]oxazines from $\mathrm{N}$-(2-vinylphenyl)amides and thiols employing mixture of $\mathrm{K}_{2} \mathrm{~S}_{2} \mathrm{O}_{8}$-activated charcoal in aqueous acetonitrile solutional $50{ }^{\circ} \mathrm{C}$ reported in this work.

ultra-violet radiation, persulfate affords a powerful one-electron oxidant such as sulfate anion-radical $\left(\mathrm{SO}_{4}{ }^{--}, E^{\circ}=2.5-3.1 \mathrm{~V}\right)$ that has longer life span than $\mathrm{HO}^{\star}$ precursors, hydrogen peroxide and ozone. In spite of this potentiality, to the best of our knowledge, the use of persulfate for the synthesis of sulfonated benzo $[d][1,3]$ oxazines has never been reported. In view of this and in continuation of our ongoing attention to explore the applications of persulfate, ${ }^{12}$ herein we disclose our findings on the preparation of 2,4-aryl-4-((arylsulfonyl)methyl)-4H-benzo[ $d]$ [1,3]oxazines from $N$-(2-vinylphenyl)amides and thiols by employing mixture of $\mathrm{K}_{2} \mathrm{~S}_{2} \mathrm{O}_{8}$-activated charcoal in aqueous acetonitrile solution at $50{ }^{\circ} \mathrm{C}$ (Scheme 2). Furthermore,

Table 1 Selected results of screening the optimal conditions for the synthesis of 2,4-aryl-4-((arylsulfonyl)methyl)-4H-benzo[d][1,3]oxazines from $N$-(2-vinylphenyl)amides and thiols ${ }^{a}$

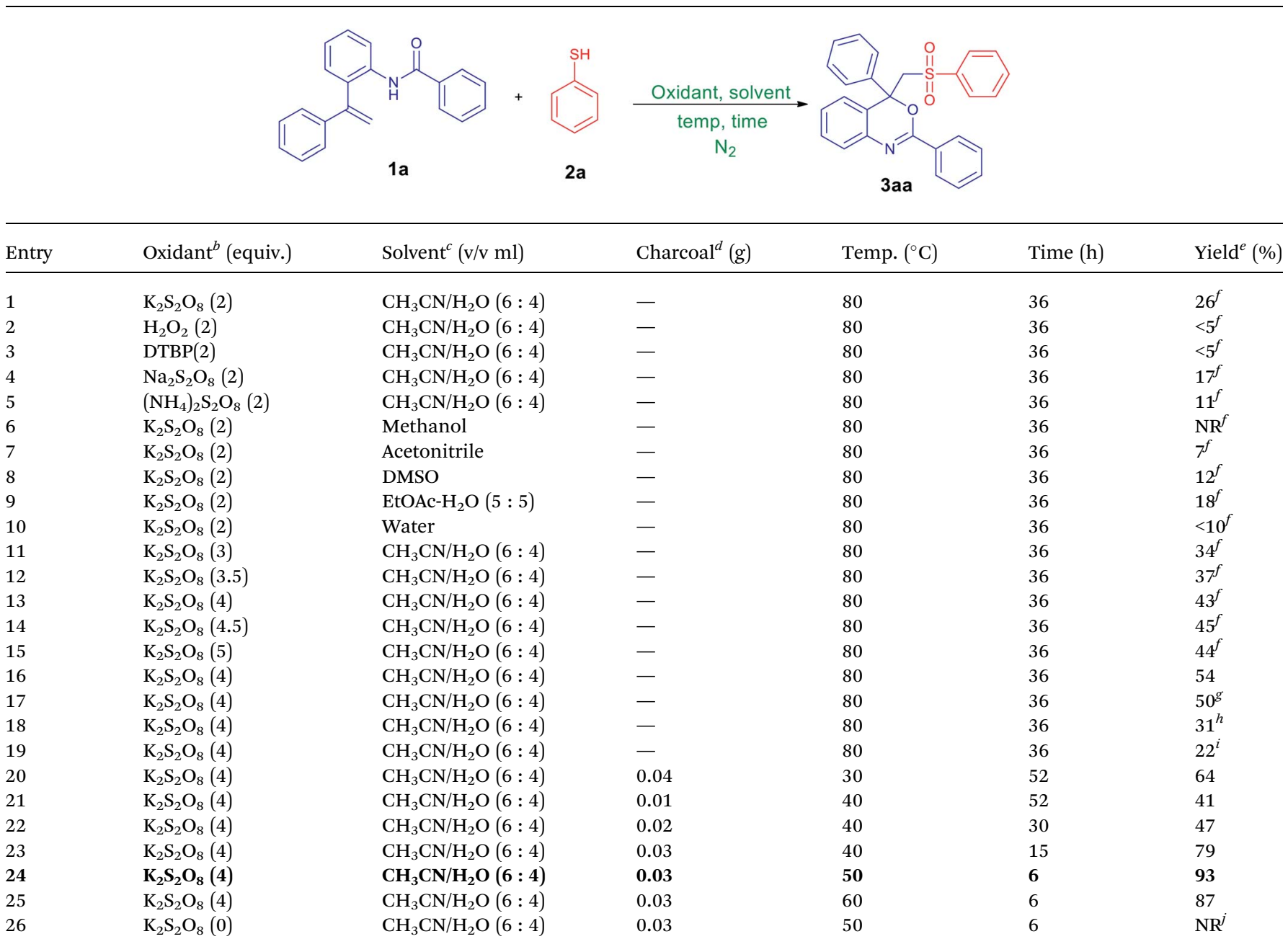

${ }^{a}$ Unless stated otherwise, all reactions were performed in a Schlenk tube with $N$-(2-(1-phenylvinyl)phenyl)benzamide (1a, 1.0 mmol), benzenethiol $(2 \mathrm{a}, 3.0 \mathrm{mmol})$ and $\mathrm{K}_{2} \mathrm{~S}_{2} \mathrm{O}_{8}$-activated charcoal in solvent at elevated temperature under nitrogen gas atmosphere. ${ }^{b}$ Used as received from commercial source. ${ }^{c}$ Distilled prior to use. ${ }^{d}$ Obtained from commercial source, $c f$. ESI. ${ }^{e}$ Isolated yields. ${ }^{f} 2.0$ equiv. of benzenethiol used. ${ }^{g} 4.0$ equiv. of benzenethiol used. ${ }^{h}$ Reaction open to air. ${ }^{i}$ Reaction performed under $\mathrm{O}_{2}$ atmosphere. ${ }^{j}$ Thiol got dimerized into disulfide. NR; no reaction. DTBP; di-tert-butyl peroxide. 
a plausible mechanism for the reaction is reported, vide infra. Especially, this is a simple and highly efficient method for the construction of $\mathrm{C}-\mathrm{S}, \mathrm{C}-\mathrm{O}$ and $\mathrm{S}-\mathrm{O}$ bonds in one step and utilizes, at the first time, easily accessible $\mathrm{K}_{2} \mathrm{~S}_{2} \mathrm{O}_{8}$-activated charcoal mixture and thiols, respectively, as an oxidant and sulfonylating precursors.

\section{Results and discussion}

We chose $N$-(2-(1-phenylvinyl)phenyl)benzamide (1a, $1.0 \mathrm{mmol})$ and benzenethiol (2a, $2.0 \mathrm{mmol}$ ) as model substrates to optimize conditions for this reaction, and the obtained results are summarized in Table 1. By using $2.0 \mathrm{mmol}$ of $\mathrm{K}_{2} \mathrm{~S}_{2} \mathrm{O}_{8}$ as an oxidant and $\mathrm{CH}_{3} \mathrm{CN} / \mathrm{H}_{2} \mathrm{O}(6: 4, \mathrm{v} / \mathrm{v} \mathrm{mL})$ as a solvent, the mixture of $1 \mathrm{a}$ and $2 \mathrm{a}$ was heated at $80^{\circ} \mathrm{C}$ under nitrogen gas atmosphere for $36 \mathrm{~h}$. Fortunately, the expected sulfonated oxindole, i.e., 2,4diphenyl-4-((phenylsulfonyl)methyl)-4H-benzo[ $d][1,3]$ oxazine (3aa) was produced in $26 \%$ yield (Table 1 , entry 1 ). The product 3aa was isolated and characterized by NMR and mass analysis (ESI). Encouraged by this result, 2.0 equiv., of different oxidants include $\mathrm{Na}_{2} \mathrm{~S}_{2} \mathrm{O}_{8},\left(\mathrm{NH}_{4}\right)_{2} \mathrm{~S}_{2} \mathrm{O}_{8}$, hydrogen peroxide and di-tertbutyl peroxide (DTBP) (Table 1, entries 2-5) were tested, and $\mathrm{K}_{2} \mathrm{~S}_{2} \mathrm{O}_{8}$ was found to be the best choice (Table 1, entry 1 ). Thus, $\mathrm{K}_{2} \mathrm{~S}_{2} \mathrm{O}_{8}$ was taken as an oxidant for further all optimizations and reactions. Replacing reaction medium $\mathrm{CH}_{3} \mathrm{CN} / \mathrm{H}_{2} \mathrm{O}(6: 4$, v/v $\mathrm{mL}$ ) with other common solvents such as methanol, acetonitrile, DMSO, water and EtOAc- $\mathrm{H}_{2} \mathrm{O}(5: 5, \mathrm{v} / \mathrm{v} \mathrm{mL})$ could also afforded the desired product 3aa, but in poor yield (Table 1, entries 6-10). To improve the product yield, we then investigated the stoichiometry of $\mathrm{K}_{2} \mathrm{~S}_{2} \mathrm{O}_{8}$ to substrate $\mathrm{N}$-(2-(1-phenylvinyl)phenyl)benzamide (1a). A slightly improved yield (43\%) of 3aa was noticed by increasing the amount of $\mathrm{K}_{2} \mathrm{~S}_{2} \mathrm{O}_{8}$ to 4.0 equiv. (Table 1, entries 11-13); however further raising the amount of $\mathrm{K}_{2} \mathrm{~S}_{2} \mathrm{O}_{8}$ did not improve the reaction efficiency drastically (Table 1, entries 14-15). Under similar conditions, the reaction gave $54 \%$ of product (3aa) with higher quantity of

Table 2 Substrate scope for the synthesis of 2,4-aryl-4-((arylsulfonyl)methyl)-4H-benzo[d][1,3]oxazines from various $N$-(2-vinylphenyl)amides and benzenethiol ${ }^{a}$

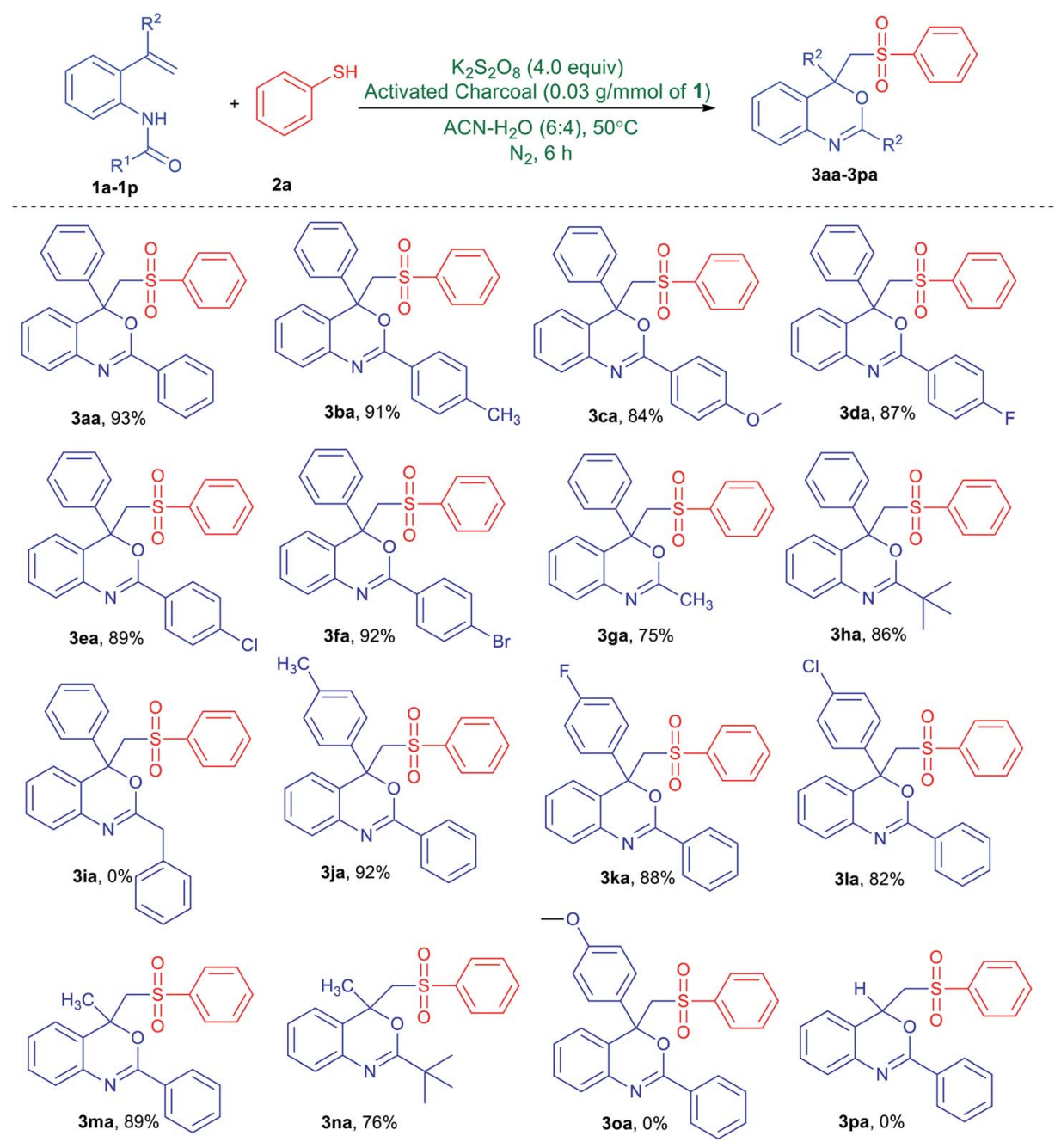

${ }^{a}$ Unless stated otherwise, all reactions were performed in a Schlenk tube with $N$-(2-vinylphenyl)amides (1a-1p, 1.0 mmol), benzenethiol (2a, 3.0 $\mathrm{mmol}), \mathrm{K}_{2} \mathrm{~S}_{2} \mathrm{O}_{8}(4.0 \mathrm{mmol})$ and activated charcoal $(0.03 \mathrm{~g})$ in $\mathrm{CH}_{3} \mathrm{CN} / \mathrm{H}_{2} \mathrm{O}(6: 4, \mathrm{v} / \mathrm{v} \mathrm{mL})$ under nitrogen gas atmosphere at $50{ }^{\circ} \mathrm{C}$ for $6 \mathrm{~h}$. 
benzenethiol (3.0 equiv., Table 1, entry 16). Additional optimizations revealed that the reaction atmosphere was crucial for outcome of the reaction. The reaction proceeded efficiently under nitrogen gas atmosphere while the involvement of air or molecular oxygen brings down yield of 3aa, $c f$. entries 18 and 19 in Table 1 . To further improve the product yield, we decided to activate the persulfate by a mild protocol. As the productivity of sulfate radicals from persulfate can be influenced by the activation types.

Recently, granulated activated carbon has been reported to successfully activate persulfate under a mild condition. ${ }^{13}$ It has a certain advantage in being non-metallic species free from metal leaching problems. Also, the activation of persulfate by granulated activated carbon proceeds on the surface of activated carbon during the radical propagation mechanism. ${ }^{14}$ Thus, the influence of activated charcoal was studied for the formation of 3aa from 1a and 2a under the reaction conditions mentioned in entry 16 of Table 1 . By addition of $40 \mathrm{mg}$ of activated charcoal to the mixture of 1a, $2 \mathrm{a}$ and $\mathrm{K}_{2} \mathrm{~S}_{2} \mathrm{O}_{8}$ in $\mathrm{CH}_{3} \mathrm{CN} / \mathrm{H}_{2} \mathrm{O}(6: 4, \mathrm{v} / \mathrm{v} \mathrm{mL})$ at room temperature, expected product 3 aa was obtained in $64 \%$ yield (Table 1, entry 20). However, rate of the reaction was too low (52 h). More examinations revealed that the complete conversion of mixture of $1 \mathrm{a}$ (1.0 equiv.) and $2 \mathrm{a}$ (3.0 equiv.) to 3 aa in $93 \%$ yield required $\mathrm{K}_{2} \mathrm{~S}_{2} \mathrm{O}_{8}$ (4.0 equiv.) and activated charcoal $\left(0.03 \mathrm{~g} \mathrm{mmol}{ }^{-1}\right.$ of 1a) in $\mathrm{CH}_{3} \mathrm{CN} / \mathrm{H}_{2} \mathrm{O}(6: 4, \mathrm{v} / \mathrm{v} \mathrm{mL})$ at $50{ }^{\circ} \mathrm{C}$ for $6 \mathrm{~h}$ (Table 1, entry 24). Control experiments revealed that $\mathrm{K}_{2} \mathrm{~S}_{2} \mathrm{O}_{8}$ (Table 1, entry 26) was essential, and no desired product was detected in its absence. From these experiments, we determined the optimized conditions as: $N$-(2-vinylphenyl)amide (1.0 equiv.), thiol (3.0 equiv.), $\mathrm{K}_{2} \mathrm{~S}_{2} \mathrm{O}_{8}$ (4.0 equiv.), and activated charcoal $\left(0.03 \mathrm{~g} \mathrm{mmol}^{-1}\right.$ of $\mathrm{N}$-(2-vinylphenyl)amide) in $\mathrm{CH}_{3} \mathrm{CN} / \mathrm{H}_{2} \mathrm{O}(6: 4, \mathrm{v} / \mathrm{v} \mathrm{mL})$ under nitrogen gas atmosphere at $50{ }^{\circ} \mathrm{C}$ for $6 \mathrm{~h}$ (Table 1, entry 24).
With the optimized conditions in hand, the substrate scope and functional group tolerance was studied and the obtained results are presented in Table 2 . First, the reactivity of $\mathrm{N}$-(2-vinylphenyl)amides with substituent on the benzamide ring (1a-1i) was studied. Indeed, this protocol was found applicable to both electron-donating group and electron-withdrawing group substituent. For instances, methyl-, methoxy-, fluoro-, chloro- and bromo-substituted $\mathrm{N}$ (2-vinylphenyl)amides provided the corresponding desired products (3ba-3fa) in $84-92 \%$ yields. Notably, the amides with alkyl substituent, such as methyl and tert-butyl groups were effective for this reaction and converted to the corresponding benzo[d][1,3]oxazines (3ga and $\mathbf{3 h a}$ ) in moderate to good yields. Nevertheless, no desired product (3ia) could be collected when benzyl-substituted $N$-(2-vinylphenyl) amide was treated with benzenethiol, $c f$. Table 2 . Next, we studied the scope of substituted alkenes $(\mathbf{1 j} \mathbf{j} \mathbf{1 p})$ in the reaction system. Various substituent include tolyl-, 4-fluorophenyl and 4-chlorophenyl at the $\alpha$-position of styrenes, afforded products (3ja-3la) in good yields. Likewise, the present system could also be employed to $N$-(2-(prop-1-en-2yl)phenyl)benzamide and $N$-(2-(prop-1-en-2-yl)phenyl) pivalamide giving products (3ma and 3na) with a yield of $89 \%$ and $76 \%$ respectively. However, no desired product (3oa or 3pa) could be collected when either $N$-(2-(1-(4methoxyphenyl)vinyl)phenyl)benzamide or monosubstituted alkene such as $N$-(2-vinylphenyl)benzamide was treated with benzenethiol, $c f$. Table 2 .

To further explore the substrate scope, we then studied the scope of thiols (Table 3). Thiols with methyl-, methoxy- and chloro-group at the para-position of the arene ring produced the

Table 3 Substrate scope for the synthesis of 2,4-aryl-4-((arylsulfonyl)methyl)-4H-benzo[d][1,3]oxazines from $N$-(2-(1-phenylvinyl)phenyl) benzamide and various thiols ${ }^{a}$

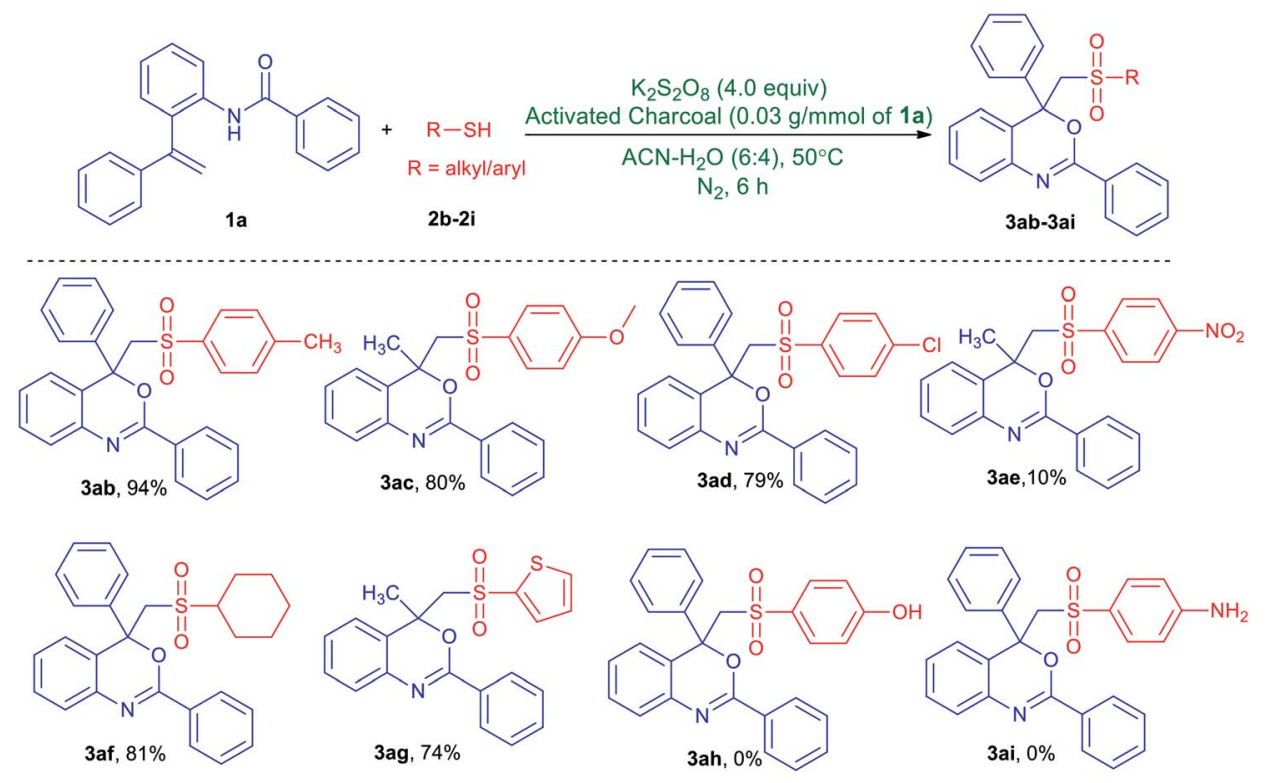

${ }^{a}$ Unless stated otherwise, all reactions were performed in a Schlenk tube with $N$-(2-(1-phenylvinyl)phenyl)benzamide (1a, 1.0 mmol), thiols (2b-2i, $3.0 \mathrm{mmol}), \mathrm{K}_{2} \mathrm{~S}_{2} \mathrm{O}_{8}(4.0 \mathrm{mmol})$ and activated charcoal $(0.03 \mathrm{~g})$ in $\mathrm{CH}_{3} \mathrm{CN} / \mathrm{H}_{2} \mathrm{O}(6: 4, \mathrm{v} / \mathrm{v} \mathrm{mL})$ under nitrogen gas atmosphere at $50{ }^{\circ} \mathrm{C}$ for $6 \mathrm{~h}$. 


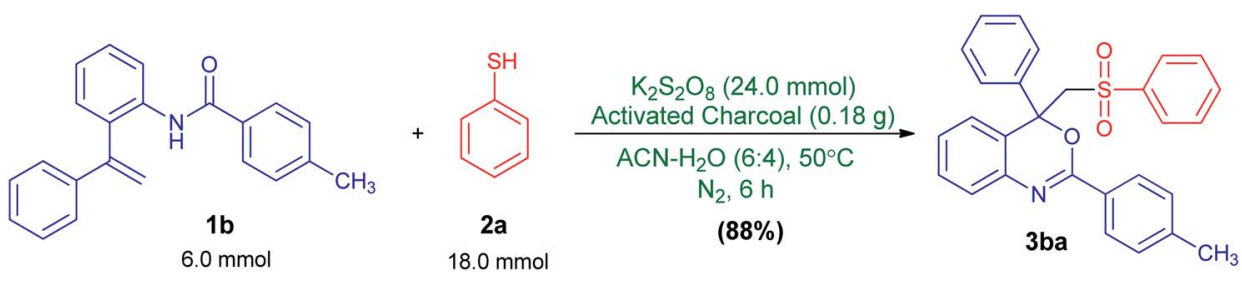

Scheme 3 Gram-scale synthesis.

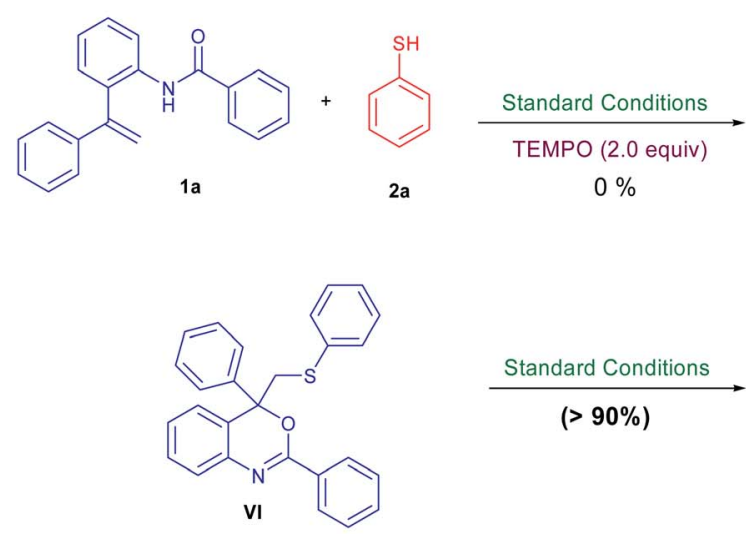

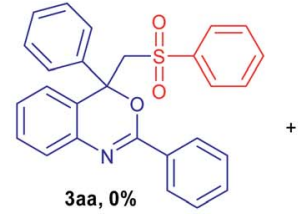

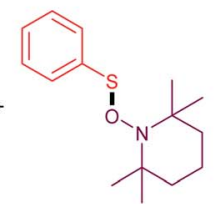

Eq. 1

Detected by GCMS

Calculated for $\mathrm{C}_{15} \mathrm{H}_{24} \mathrm{NOS} 266.16$ found 266.119 .

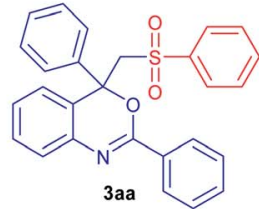

Scheme 4 Control experiments for mechanistic studies.

desired products in excellent yields (3ab-3ad). However, 4nitrobenzenethiol leads to a dramatic decrease of the reaction efficiency and afforded product $3 \mathrm{ae}$ in $10 \%$ yield. To our delight, this protocol is also applicable to cyclohexanethiol and thiophene-2-thiol and was converted to the corresponding products (3af and 3ag) in significant yield. Unfortunately, thiols with a hydroxy or an amino group on the arene ring could not afford the desired product (3ah and 3ai).

This reaction could also be performed on a gram scale. As shown in Scheme 3, treatment of $1.9 \mathrm{~g}(6 \mathrm{mmol})$ of 4-methyl- $\mathrm{N}-(2-$ (1-phenylvinyl)phenyl)benzamide (1) with 3 equiv. of benzenethiol (2a) under the optimized reaction conditions (Table 1, entry 24) afforded the desired 4-phenyl-4-((phenylsulfonyl)methyl)-2-ptolyl-4H-benzo[ $d][1,3]$ oxazine (3ba) in $88 \%(2.4 \mathrm{~g})$ isolated yield, clearly demonstrating the preparative practicality of this protocol.

To understand the mechanism of this transformation, some control experiments were carried out as described in Scheme 4. On addition of 2 equiv. of radical scavenger 2,2,6,6tetramethylpiperidine-1-oxyl (TEMPO) under the standard conditions, no desired product (3aa) was observed (instead thio1-TEMPO adduct detected by GCMS analysis). In other words, TEMPO completely inhibited this reaction indicating that the reaction follows a radical pathway. ${ }^{7,8}$ In addition, the sulfurcontaining benzo[d][1,3] oxazine (VI) could also be converted to the sulfone-containing benzo[ $d][1,3]$ oxazine (3aa) in good yield under similar reaction conditions in the absence of thiol. Thus, it would be reasonable to deduce that sulfur-containing benzo[d][1,3] oxazine (VI) was the plausible intermediate in this reaction. ${ }^{6}$

On the basis of the results described above and previous reports, a plausible mechanism is outlined in Scheme 5. Initially, the activated charcoal-assisted heterolytic cleavage of $\mathrm{S}_{2} \mathrm{O}_{8}{ }^{2-}$ affords sulfate radical anions $\left(\mathrm{SO}_{4}{ }^{-}\right)$, which then abstract the hydrogen atoms from the thiol (2) to afford a sulfur-centered sulfonyl radical (II). ${ }^{13,14}$ The addition of radical II to $\mathrm{C}=\mathrm{C}$ bond of $\mathrm{N}$-(2-vinylphenyl)amide (1) would lead to the formation of alkyl radical III. Later, III undergoes an intramolecular radical cyclization to provide a new radical intermediate IV. Subsequently, the radical IV was further oxidized to the corresponding carbocation (V) by oxidant followed by deprotonation to afford the sulfur-containing benzo[ $[d][1,3]$ oxazine (VI). ${ }^{5}$ However, a cationic cyclization cannot be excluded completely, in which the alkyl radical intermediate III is further oxidized to

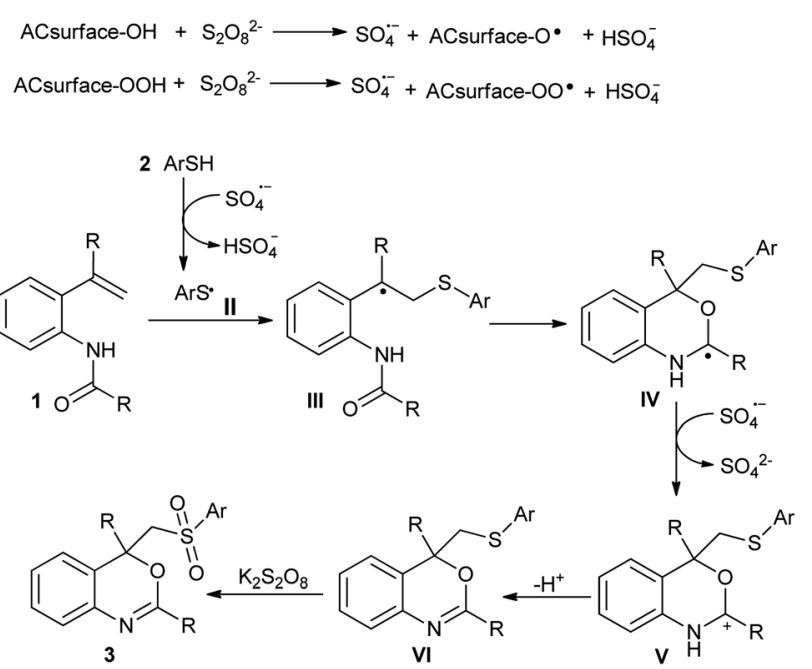

Scheme 5 A plausible mechanism for the formation of 2,4-aryl-4((arylsulfonyl)methyl)-4H-benzo[d][1,3]oxazines from $\mathrm{N}$-(2-vinylphenyl)amides and thiols. 
carbocation and subsequently trapped by the carbonyl group of amide. ${ }^{6}$ The resulting VI would be rapidly oxidized to desired sulfone-containing benzo[d][1,3] oxazine (3) by $\mathrm{K}_{2} \mathrm{~S}_{2} \mathrm{O}_{8}{ }^{7,13}$ The influence of activated charcoal on reactivity of $\mathrm{K}_{2} \mathrm{~S}_{2} \mathrm{O}_{8}$ is not clear, however, we believe that the high surface area and micro porosity of activated charcoal may play role through widespread interactions and scission of $\mathrm{S}_{2} \mathrm{O}_{8}{ }^{2-}$ to more powerful sulfate radical anions $\left(\mathrm{SO}_{4}{ }^{-{ }^{-}}\right)$that accelerates the reaction under mild conditions. ${ }^{\mathbf{1 4}}$

In summary, a mild and cost-efficient protocol was developed for the synthesis of 2,4-aryl-4-((arylsulfonyl)methyl)-4H-benzo[d] [1,3] oxazines from $\mathrm{N}$-(2-vinylphenyl)amides and thiols by employing mixture of $\mathrm{K}_{2} \mathrm{~S}_{2} \mathrm{O}_{8}$-activated charcoal in aqueous acetonitrile solution at $50{ }^{\circ} \mathrm{C}$. The facile formation of new $\mathrm{C}-\mathrm{S}, \mathrm{C}-\mathrm{O}$ and $\mathrm{S}-\mathrm{O}$ bonds take place in a one-pot procedure. Versatility of this synthetic method for a broad range of $N$-(2-vinylphenyl)amides and thiols as well as the benefits of use of easily accessible $\mathrm{K}_{2} \mathrm{~S}_{2} \mathrm{O}_{8}$ activated charcoal mixture and thiols, respectively, as an oxidant and sulfonylating precursors. Further studies on the mechanism and applications are ongoing in our laboratory.

\section{Experimental section}

General procedure for the synthesis of 2,4-aryl-4((arylsulfonyl)methyl)-4H-benzo[ []$[1,3]$ oxazines

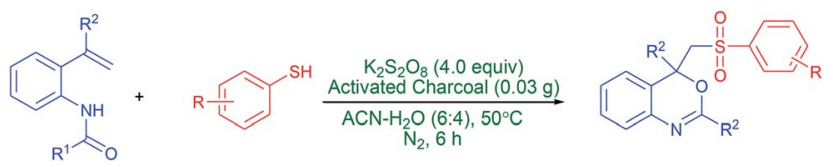

An oven-dried Schlenk-tube equipped with a magnetic stir bar was charged with $\mathrm{N}$-(2-vinylphenyl)amides $(1.0 \mathrm{mmol}, 1.0$ equiv.), thiol (3.0 mmol, 3.0 equiv.), $\mathrm{K}_{2} \mathrm{~S}_{2} \mathrm{O}_{8}$ (4.0 mmol, 4.0 equiv.) and activated charcoal (0.03 g). To this mixture, $\mathrm{CH}_{3} \mathrm{CN} /$ $\mathrm{H}_{2} \mathrm{O}(6: 4, \mathrm{v} / \mathrm{v} \mathrm{mL}, 10 \mathrm{~mL})$ was added. Then, the tube was sealed and inlet/outlet for $\mathrm{N}_{2}$ gas was provided by a side-neck. Resultant mixture was vigorously stirred under nitrogen gas atmosphere at $50{ }^{\circ} \mathrm{C}$ for $6 \mathrm{~h}$. After the completion (as indicated by TLC, $\approx 6 \mathrm{~h}$ ) volatiles were evaporated under reduced pressure and then admixed with aqueous $\mathrm{K}_{2} \mathrm{CO}_{3}$ solution $(20 \mathrm{~mL})$. The organic matters are extracted with ethyl acetate, dried over $\mathrm{Na}_{2} \mathrm{SO}_{4}$ and evaporated under reduced pressure to yield a paleyellow gummy-solid, which was purified by a column chromatography using a mixture of ethyl acetate and hexane. The identity and purity of the product was confirmed by spectroscopic analysis as well as by a comparison with authentic samples spectra, vide infra.

\section{Conflicts of interest}

There are no conflicts to declare.

\section{Acknowledgements}

Authors are gratefully acknowledge the financial support from Council of Industrial Scientific Research (CSIR), New Delhi, India, through extra mutual research grant with a project number 02(0380)/19/EMR-II. Priya and D. C., thank the CSIR, New Delhi for their senior research fellowships.

\section{References}

1 (a) N. Kumar, N. Yadav, N. Amarnath, V. Sharma, S. Shukla, A. Srivastava, P. Prasad, A. Kumar, S. Garg, S. Singh, S. Sehrawat and B. Lochab, Integrative natural medicine inspired graphene nanovehicle-benzoxazine derivatives as potent therapy for cancer, Mol. Cell. Biochem., 2019, 454, 123-138; (b) K. Zhang, M. Han, Y. Liu and P. Froimowicz, Design and synthesis of bio-based high-performance trioxazine benzoxazine resin via natural renewable resources, ACS Sustainable Chem. Eng., 2019, 7, 9399-9407; (c) Y. Lyu and H. Ishida, Natural-sourced benzoxazine resins, homopolymers, blends and composites: a review of their synthesis, manufacturing and applications, Prog. Polym. Sci., 2019, 99, 101168; (d) J. Sheng, X. Su, C. Cao and C. Chen, Synthesis of benzo[1,3] oxazines via copper(i)catalyzed cascade annulation of nitriles, aldehydes and diaryliodonium salts, Org. Chem. Front., 2016, 3, 501-504; (e) B. V. S. Reddy, R. A. Babu, M. R. Reddy, B. J. M. Reddy and $\mathrm{B}$. Sridhar, Intramolecular $\mathrm{C}-\mathrm{O} / \mathrm{C}-\mathrm{S}$ bond insertion of $\alpha$-diazoesters for the synthesis of 2 -aryl- $4 H$-benzo[d][1,3] oxazine and 2-aryl- $4 H$-benzo[d][1,3]thiazine derivatives, $R S C$ $A d v ., \quad 2014$, 4, 44629-44633; (f) A. A. A. Qahtani, T. M. A. Turki, A. A. Mousa, S. A. A. Mazroa, M. Khan and H. Z. Alkhathlan, Simple and selective synthesis of 1,3benzoxazine derivatives, Orient, J. Chem., 2012, 28, 287295; $(g)$ J. Tanabe, M. Sue, A. Ishihara and H. Iwamura, Occurrence and characterization of 2-hydroxy-1,4benzoxazin-3-one and indole hydroxylases in juvenile wheat, Biosci. Biotechnol. Biochem., 1999, 63, 1614-1617.

2 (a) W. -C. Lee, H. -C. Shen, W. -P. Hu, W. -S. Lo, C. Murali, J. K. Vandavasi and J. -J. Wang, Iodine-catalyzed, stereoand regioselective synthesis of 4 -arylidine- 4 h-benzo[d] $[1,3]$ oxazines and their applications for the synthesis of quinazoline 3-oxides, Adv. Synth. Catal., 2012, 354, 22182228; (b) Z. Tang, W. Chen, Z. Zhu and H. Liu, Synthesis of 2,3-Diaryl-3,4-dihydro-2H-1,3-benzoxazines and their fungicidal activities, J. Heterocyclic Chem., 2011, 48, 255; (c) J. Ilas, Z. Jakopin, T. Borstnar, M. Stegnar and D. Kikelj, 3,4-dihydro-2h-1,4-benzoxazine derivatives combining thrombin inhibitory and glycoprotein IIb/IIIa receptor antagonistic activity as a novel class of antithrombotic compounds with dual function, J. Med. Chem., 2008, 51, 5617-5629; (d) A. Fensome, R. Bender, R. Chopra, J. Cohen, M. A. Collins, V. Hudak, K. Malakian, S. Lockhead, A. Olland, K. Svenson, E. A. Terefenko, R. J. Unwalla, J. M. Wilhelm, S. Wolfrom, Y. Zhu, Z. Zhang, P. Zhang, R. C. Winneker and J. Wrobel, Synthesis and structureactivity relationship of novel 6-aryl-1,4- dihydrobenzo[d] 
$[1,3]$ oxazine-2-thiones as progesterone receptor modulators leading to the potent and selective nonsteroidal progesterone receptor agonist tanaproget, J. Med. Chem., 2005， 48， 5092-5095; (e) N. Dias, J.-F. Goossens, B. Baldeyrou, A. Lansiaux, P. Colson, A. D. Salvo, J. Bernal, A. Turnbull, D. J. Mincher and C. Bailly, Oxoazabenzo[de] anthracenes conjugated to amino acids: synthesis and evaluation as DNA-binding antitumor agents, Bioconjugate Chem., 2005, 16, 949-958; (f) K. Waisser, J. Gregor, L. Kubicová, V. Klimesová, J. Kunes, M. Machácek and J. Kaustová, New groups of antimycobacterial agents: 6chloro-3-phenyl-4-thioxo-2 $\mathrm{H}$-1,3-benzoxazine-2(3H)-ones

and 6-chloro-3-phenyl-2H-1,3 benzoxazine-2,4(3H)dithiones, Eur. J. Med. Chem., 2000, 35, 733-741.

3 (a) Z. Tian and D. Kim, Solid electrolyte membranes prepared from poly(arylene ether sulfone)-g-poly(ethylene glycol) with various functional end groups for lithium-ion battery, J. Membr. Sci., 2021, 621, 119023; (b) H. Li, M. Hong, A. Scarpaci, X. He, C. Risko, J. S. Sears, S. Barlow, P. Winget, S. R. Marder, D. Kim and J.-L. Brédas, Chemical stabilities of the lowest triplet state in aryl sulfones and aryl phosphine oxides relevant to OLED applications, Chem. Mater., 2019, 31, 1507-1519; (c) X. Wang, L. Chen, S. Y. Chong, M. A. Little, Y. Wu, W.-H. Zhu, R. Clowes, Y. Yan, M. A. Zwijnenburg, R. S. Sprick and A. I. Cooper, Sulfone-containing covalent organic frameworks for photocatalytic hydrogen evolution from water, Nat. Chem., 2018, 10, 1180-1189; (d) N. A. Alenazi, M. A. Hussein, K. A. Alamry and A. M. Asiri, Modified polyether-sulfone membrane: a mini review, Des. Monomers Polym., 2017, 20, 532-546; (e) M. Podgórski, C. Wang, Y. Yuan, D. Konetski, I. Smalyukhand and C. N. Bowman, Pristine polysulfone networks as a class of polysulfide-derived highperformance functional materials, Chem. Mater., 2016, 28(14), 5102-5109; (f) H. Sasabe, Y. Seino, M. Kimura and J. Kido, A m-terphenyl-modified sulfone derivative as a host material for high-efficiency blue and green phosphorescent OLEDs, Chem. Mater., 2012, 24, 1404-1406; (g) R. Nolte, K. Ledjeff, M. Bauer and R. Mülhaupt, Partially sulfonated poly (arylene ether sulfone) -A versatile proton conducting membrane material for modern energy conversion technologies, J. Membr. Sci., 1993, 83, 211-220.

4 (a) J. George, Metabolism and interactions of antileprosy drugs, Biochem. Pharmacol., 2020, 177, 113993-114001; (b) M. Ibrahim, A. Latif, A. A. Ali, A. I. Ribeiro, U. Farooq, F. Ullah, A. Khan, A. A. Harrasi, M. Ahmad and M. Ali, Macrocyclic sulfone derivatives: Synthesis, characterization, in vitro biological evaluation and molecular docking, Drug Dev. Res., 2020, DOI: 10.1002/ddr.21775; (c) M. R. Shaaban, T. A. Farghaly and A. M. R. Alsaedi, Synthesis, antimicrobial and anticancer evaluations of novel thiazoles incorporated diphenyl sulfone moiety, Polycycl. Aromat. Compd., 2020, DOI: 10.1080/10406638.2020.1837887; (d) K. A. Scott and J. T. Njardarson, Analysis of US FDAapproved drugs containing sulfur atoms, Top. Curr. Chem., 2018, 376, 1-34; (e) M. Feng, B. Tang, S. H. Liang and $\mathrm{X}$. Jiang, Sulfur containing scaffolds in drugs: synthesis and application in medicinal chemistry, Curr. Top. Med. Chem., 2016, 16, 1200-1216; $(f)$ A. L. Lorincz and R. W. Pearson, Sulfapyridine and sulfone type drugs in dermatology, Arch. Dermatol., 1962, 85, 2-16.

5 T. Liu, D. Zheng, Z. Li and J. Wu, Synthesis of sulfonated benzo $[d][1,3]$ oxazines by merging photoredox catalysis and insertion of sulfur dioxide, Adv. Synth. Catal., 2017, 360, 865-869.

$6 \mathrm{M}$. Chaitanya and P. Anbarasan, Acid-mediated oxychalcogenation of o-vinylanilides with $\mathrm{N}$-(arylthio/ arylseleno)succinimides, Org. Lett., 2018, 20, 1183-1186.

7 J. Wu, Y. Zong, C. Zhao, Q. Yan, L. Sun, Y. Li, J. Zhao, Y. Ge and $\mathrm{Z}$. Li, Silver or cerium-promoted free radical cascade difunctionalization of o-vinylanilides with sodium aryl- or alkylsulfinates, Org. Biomol. Chem., 2019, 17, 794-797.

8 T.-J. He, W.-Q. Zhong and J.-M. Huang, The synthesis of sulfonated 4H-3,1-benzoxazines via an electro-chemical radical cascade cyclization, Chem. Commun., 2020, 56, 2735-2738.

9 (a) J. K. Laha, M. K. Hunjan, S. Hegde and A. Gupta, Aroylation of electron-rich pyrroles under minisci reaction conditions, Org. Lett., 2020, 22, 1442-1447; (b) H. Tian, H. Yang, C. Tian, G. An and G. Li, Cross-dehydrogenative coupling of strong $\mathrm{C}\left(\mathrm{sp}^{3}\right)-\mathrm{H}$ with $\mathrm{N}$-heteroarenes through visible-light-induced energy transfer, Org. Lett., 2020, 22, 7709-7715; (c) V. D. Nguyen, V. T. Nguyen, G. C. Haug, H. T. Dang, H. D. Arman, W. C. Ermler and O. V. Larionov, Rapid and chemodivergent synthesis of N-heterocyclic sulfones and sulfides: mechanistic and computational details of the persulfate-initiated catalysis, ACS Catal., 2019, 9, 4015-4024; (d) G. K. Rastogi, B. Deka, M. L. Deb and P. K. Baruah, Diastereoselective $\mathrm{sp}^{3}-\mathrm{C}-\mathrm{H}$ functionalization of arylmethyl ketones and transformation of $E$ - to Z-products through photocatalysis, Eur. J. Org. Chem., 2019, 2020, 424-428; (e) S. Manna and K. R. Prabhu, Visible-light-mediated direct decarboxylative acylation of electron- deficient heteroarenes using $\alpha$ ketoacids, J. Org. Chem., 2019, 84, 5067-5077.

10 (a) W. Dong, T. Cai, Y. Liu, L. Wang, H. Chen, W. Zeng, J. Li and W. Li, Rapid removal of organic pollutants by a novel persulfate/brochantite system: Mechanism and implication, J. Colloid Interface Sci., 2021, 585, 400-407; (b) G. Chen, Y. Yu, L. Liang, X. Duan, R. Li, X. Lu, B. Yan, N. Li and S. Wang, Remediation of antibiotic wastewater by coupled photocatalytic and persulfate oxidation system: A critical review, J. Hazard. Mater., 2021, 408, 124461; (c) J. Lee, U. Gunten and J.-H. Kim, Persulfate-based advanced oxidation: critical assessment of opportunities and roadblocks, rapid removal of organic pollutants by a novel persulfate/brochantite system: mechanism and implication, Environ. Sci. Technol., 2020, 54, 3064-3081; (d) D. Zhi, Y. Lin, L. Jiang, Y. Zhou, A. Huang, J. Yang and L. Luo, Remediation of persistent organic pollutants in aqueous systems by electrochemical activation of persulfates: A review, J. Environ. Manage., 2020, 260, 110125; (e) S. Wacławek, H. V. Lutze, K. Grübel, V. V. T. Padil, M. Černík and D. D. Dionysiou, Chemistry of 
persulfates in water and wastewater treatment: a review, Chem. Eng. J., 2017, 330, 44-62; $(f)$ L. W. Matzek and K. E. Carter, Activated persulfate for organic chemical degradation: A review, Chemosphere, 2016, 151, 178-188; $(g)$ B.-T. Zhang, Y. Zhang, Y. Teng and M. Fan, Sulfate radical and its application in decontamination technologies, Crit. Rev. Environ. Sci. Technol., 2015, 45, 1756-1800; (h) C. Chen, Y. Cao, X. Wu, Y. Cai, J. Liu, L. Xu, K. Ding and L. Yu, Energy saving and environment-friendly elementtransfer reactions with industrial application potential, Chin. Chem. Lett., 2020, 31, 1078-1082.

11 (a) S. F. C. Acevedoa, L. A. B. Buitrago, D. D. Dionysiou and F. M. Martínez, Ultraviolet light-mediated activation of persulfate for the degradation of cobalt cyano complexes, $J$. Hazard. Mater., 2020, 392, 122389-122396; (b) J. Yu, H. Feng, L. Tang, Y. Pang, G. Zeng, Y. Lu, H. Dong, J. Wang, Y. Liu, C. Feng, J. Wang, B. Peng and S. Ye, Metalfree carbon materials for persulfate-based advanced oxidation process: Microstructure, property and tailoring, Prog. Mater. Sci., 2020, 111, 100654; (c) W. Song, J. Li, Z. Wang and X. Zhang, A mini review of activated methods to persulfate-based advanced oxidation process, Water Sci. Technol., 2019, 79, 573-579; (d) B. Wang, Y.-Ni. Li and L. Wang, Metal-free activation of persulfates by corn stalk biochar for the degradation of antibiotic norfloxacin: Activation factors and degradation mechanism, Chemosphere, 2019, 237, 124454-124462; (e) I. A. Ike, K. G. Linden, J. D. Orbell and M. Duke, Critical review of the science and sustainability of persulphate advanced oxidation processes, Chem. Eng. J., 2018, 338, 651-669; (f) J. Wang and S. Wang, Activation of persulfate (PS) and peroxymonosulfate (PMS) and application for the degradation of emerging contaminants, Chem. Eng. J., 2018, 334, 1502-1517; ( $g$ ) R. Xiao, Z. Luo, Z. Wei, S. Luo, R. Spinney, W. Yang and D. D. Dionysiou, Activation of peroxymonosulfate/persulfate by nanomaterials for sulfate radical-based advanced oxidation technologies, Curr. Opin. Chem. Eng., 2018, 19, 51-58.

12 (a) Priya and P. Natarajan, An overview on the organic synthesis and transformations initiated by sulfate radical anions $\left(\mathrm{SO}^{\cdot-}\right)$ produced from aqueous persulfate solutions under transition metal-free conditions, in Modern Green Chemistry and Heterocyclic Compounds, ed. R. S. Shinde and A. K. Haghi, Apple Academic Press, 2020, ISBN: 978-177188-8325; (b) P. Natarajan, Priya and D. Chuskit, Transition-metal-free and organic solvent-free conversion of $\mathrm{N}$-substituted 2-aminobiaryls into corresponding carbazoles via intramolecular oxidative radical cyclization induced by peroxodisulfate, Green Chem., 2017, 19, 5854-5861.

13 (a) J. Li, K. Zhu, R. Li, X. Fan, H. Lin and H. Zhang, The removal of azo dye from aqueous solution by oxidation with peroxydisulfate in the presence of granular activated carbon: Performance, mechanism and reusability, Chemosphere, 2020, 259, 127400; (b) M. Forouzesh, A. Ebadi, A. A. Meybodi and R. Khoshbouy, Transformation of persulfate to free sulfate radical over granular activated carbon: Effect of acidic oxygen functional groups, Chem. Eng. J., 2019, 374, 965-974; (c) M. Forouzesh, A. Ebadi and A. A. Meybodi, Degradation of metronidazole antibiotic in aqueous medium using activated carbon as a persulfate activator, Sep. Purif. Technol., 2019, 210, 145-151; (d) Y. -Y. Ahn and E. T. Yun, Heterogeneous metals and metal-free carbon materials for oxidative degradation through persulfate activation: A review of heterogeneous catalytic activation of persulfate related to oxidation mechanism, Korean J. Chem. Eng., 2019, 36, 1767-1779; (e) J. Chen, W. Hong, T. Huang, L. Zhang, W. Li and Y. Wang, Activated carbon fiber for heterogeneous activation of persulfate: implication for the decolorization of azo dye, Environ. Sci. Pollut. Res., 2016, 23, 18564-18574; (f) S. Yang, X. Yang, X. Shao, R. Niu and L. Wang, Activated carbon catalyzed persulfate oxidation of Azo dye acid orange 7 at ambient temperature, J. Hazard. Mater., 2011, 186, 659-666.

14 (a) M. Forouzesh, A. Ebadi and A. A. Meybodi, Continuous fixed-bed oxidation of metronidazole by the sulfate radical based process over nitric acid treated granular activated carbon, J. Water Process. Eng., 2020, 36, 101280; (b) C. Liang, Y. -T. Lin and W. -H. Shih, Treatment of trichloroethylene by adsorption and persulfate oxidation in batch studies, Ind. Eng. Chem. Res., 2009, 48, 8373-8380. 